\title{
Perancangan User Interface Game Angklung dengan Metode User Centered Design (Studi Kasus Saung Angklung Udjo)
}

\author{
Wahyu Kurniawan Hartanto ${ }^{\# 1}$, Danang Junaedi. ${ }^{\# 2}$, Emil Robert Kaburuan ${ }^{\# 3}$ \\ \#1,2 Fakultas Informatika, Universitas Telkom, Bandung \\ Jl. Telekomunikasi Terusan Buah Batu \\ Bandung 40257 Indonesia \\ \#3 Magister Manajemen Sistem Informasi, Universitas Bina Nusantara, Jakarta \\ Jl. Kebon Jeruk Raya No. 27 \\ Jakarta 11530 Indonesia \\ ${ }^{1}$ wahyukurniawanh@students.telkomuniversity.ac.id, ${ }^{2}$ danangJunedi@ @ telkomuniversity.ac.id, ${ }^{3}$ \\ Emil.Kabururan@binus.edu
}

\begin{abstract}
Angklung is a unique Indonesian culture that has been recognized by UNESCO since 2010. One of preservation of angklung culture, the Bandung city government has made Saung Angklung Udjo as place to preserve angklung. Along with the development of technology, angklung games for smartphones have been developed. In term of game, usability aspect is one of the important aspects that connected between users and games. Based on the usability evaluation that using the Quality in Use Integrated Measurement (QUIM) method applied to some applications and angklung games, the average test for all factors has not fulfilled the usability aspect, that caused problems in users experience when using the angklung game application. Therefore, it is necessary to design the user interface for the angklung game application so that it can be used in playing angklung. The method used for designing the user interface of angklung game application is a user centered design method that focuses on characteristics, tasks, environments of users. Based on the evaluation using QUIM Belajar bermain Angklung application is able to meet the requirements and abilities of users, this can be seen from the results of the lowest usability value is $86 \%$ which means it has met the usability aspect.
\end{abstract}

Keywords: Angklung, Culture, Game, QUIM, User Interface, User Centered Design

\begin{abstract}
Abstrak
Angklung adalah kebudayaan khas Indonesia yang telah diakui UNESCO sejak tahun 2010. Salah satu bentuk pelestarian terhadap kebudayaan angklung, pemerintah kota Bandung menjadikan Saung Angklung Udjo sebagai tempat untuk melestarikan angklung. Seiring perkembangan teknologi, game angklung untuk smartphone sudah banyak dikembangkan. Pada suatu game, aspek usability merupakan salah satu aspek penting penghubung antara user dengan game. Berdasarkan evaluasi usability yang dilakukan menggunakan metode Quality in Use Integrated Measurement (QUIM) kepada beberapa aplikasi dan game angklung diperoleh rata- rata pengujian untuk semua faktor belum memenuhi aspek usability yang mengakibatkan pengguna mengalami kendala dalam menggunakan aplikasi game angklung. Oleh sebab itu perlu dilakukan perancangan user interface terhadap aplikasi game angklung supaya dapat digunakan dalam bermain angklung. Metode yang digunakan untuk perancangan user interface aplikasi game angklung adalah metode user centered design yang berfokus pada characteristics, task, environments dari pengguna. Berdasarkan hasil evaluasi dengan menggunakan QUIM aplikasi game Belajar Bermain Angklung dapat memenuhi kebutuhan dan kemampuan pengguna, hal ini terlihat dari nilai usability terendah sebesar $86 \%$ yang artinya sudah memenuhi aspek usability.
\end{abstract}

Kata Kunci: Angklung, Kebudayaan, Game, QUIM, User Interface, User Centered Design 
Wahyu K. Hartanto et.al.

\section{PENDAHULUAN}

A ngklung adalah kebudayaan khas Indonesia yang banyak dijumpai di daerah Jawa Barat. Angklung telah terdaftar sebagai Masterpiece of Oral and Intangible Heritage of Humanity dari UNESCO sejak November 2010 [1]. Sebagai salah satu warisan kebudayaan yang telah diakui oleh UNESCO, angklung harus terus dijaga dan dilestarikan dengan belajar bermain angklung sebagai salah satu bentuk partisipasi dalam pelestarian kebudayaan angklung. Pemerintah Kota Bandung sendiri telah mengeluarkan Peraturan Daerah Kota Bandung Nomor 05 Tahun 2012 tentang Pelestarian Seni Tradisional [2], sehingga kebudayaan seperti angklung dapat dilestarikan. Salah satu upayanya adalah dengan menetapkan Saung Angklung Udjo sebagai cagar budaya untuk melestarikan kebudayaan angklung. Seiring perkembangan teknologi, game angklung untuk smartphone sudah dikembangkan dan setiap orang dengan mudah mengunduh game angklung dari Playstore. Dalam sebuah game, aspek usability adalah salah satu hal yang perlu diperhatikan. Usability berkaitan erat dengan user interface karena suatu user interface merupakan penghubung antara user dan game dalam berkomunikasi [3]. Suatu usability yang baik adalah usability yang dapat memenuhi kebutuhan dari penggunanya melalui user interface. Berdasarkan hasil evaluasi usability menggunakan metode QUIM (Quality in User Integrated Measurement) [4] terhadap 3 aplikasi angklung yang dipilih sebagai sample, dihasilkan ratarata nilai usability kurang dari $69 \%$. Hal tersebut menandakan tingkat usability dari aplikasi game angklung yang dievaluasi belum memenuhi batas minimum usability yang diterima [5], sehingga terdapat masalah pada user interface pada aplikasi game angklung yang telah dievaluasi, akibatnya pengguna mengalami kendala dalam menggunakan aplikasi game angklung tersebut.

Berdasarkan latar belakang masalah tersebut, dilakukan perancangan ulang model user interface pada aplikasi game angklung yang dapat memudahkan pengguna untuk belajar bermain angklung. Metode yang akan digunakan untuk permodelan user interface untuk aplikasi ini adalah metode user centered design, metode ini dipilih karena manfaat dari penerapan metode user centered design dapat memberikan pendefinisian kebutuhan lebih akurat dari pengguna sistem sehingga dapat menghasilkan user interface yang sesuai dengan pengalaman dan kebutuhan pengguna [6]. Melalui metode ini diharapkan dapat memberikan model user interface yang baik dan memenuhi aspek usability user interface game angklung.

\section{TINJAUAN PUSTAKA}

Tinjauan pustaka yang digunakan pada pada penelitian ini sebagai berikut:

a) User Centered Design adalah metode dalam mendesain yang berpusat pada penggunanya [6]. Proses desain User Centered Design (UCD) terdiri dari [7]:

1. Specify the context of use

Mengidentifikasi konteks pengguna. Konteks pengguna berisi mengenai pengguna yang akan menggunakan aplikasi dan menentukan kondisi digunakannya aplikasi oleh pengguna. Data konteks pengguna diperoleh dari pengambilan data kepada pengguna. Hasil yang didapatkan dari tahap ini berupa characteristic, behavior, needs dan motivation dari pengguna. Hasil dari tahap ini berupa persona, kemudian dijadikan sebagai data kebutuhan pengguna.

2. Specify user requirements

Mengidentifikasi kebutuhan pengguna untuk menentukan kebutuhan dari aplikasi, data kebutuhan dari pengguna diperoleh dari pengguna konteks pengguna. Hasil yang didapatkan dari tahap ini berupa data kebutuhan dari aplikasi sesuai dengan kebutuhan pengguna. Hasil pada tahap ini kemudian dijadikan sebagai data kebutuhan dari pengguna terhadap aplikasi yang akan dibangun

3. Produce design solution

Merancang solusi desain berdasarkan data kebutuhan dari pengguna, proses ini dilakukan dalam beberapa proses, dimulai dari merancang konsep desain, membuat desain menjadi lebih detail dan konkret kemudian mengimplementasikan desain. Hasil yang didapatkan dalam bentuk yang lebih detail dan implementasi dari sistem. Hasil pada tahap ini kemudian dijadikan sebagai solusi desain sistem 


\section{Evaluation againt requirements}

Menguji solusi desain sistem untuk menilai apakah solusi desain telah dapat sesuai dengan kebutuhan dari pengguna. Hasil yang didapatkan dari tahap ini berupa data pengujain solusi aplikasi sesuai dengan kebutuhan dari pengguna dan feedback.

b) Quality in Use Integrated Measurement (QUIM) digunakan untuk mengukur pengguna perangkat lunak dan mengidentifikasi masalah pada perangkat lunak [8]. Faktor usabilitly yang terdapat pada QUIM antara lain efficiency, effectiveness, prductivity, satisfaction, learnability, safety, trustfulness, accessibility, universality dan usefulness [9]. Cara mengolah hasil pengujian menggunakan QUIM yaitu hasil pengujian yang diperoleh berupa bobot nilai yang diperoleh dari respon pengguna. Selanjutnya nilai yang diperoleh menjadi total nilai kumulatif pertanyaan dari masing- masing faktor yang ada, dari total nilai nilai kumulatif yang diperoleh dibagi dengan total maksimum nilai kumulatif yang diperoleh dari masing masing tahap sehingga menghasilkan persentase dari nilai QUIM yang diperoleh. [9]

\section{ALUR PERMODELAN}

Metode User Centered Design dijadikan sebagai acuan alur permodelan aplikasi game Belajar Bermain Angklung. Gambar 1 menjelaskan langkah-langkah dalam alur permodelan yang telah dilaksanakan.

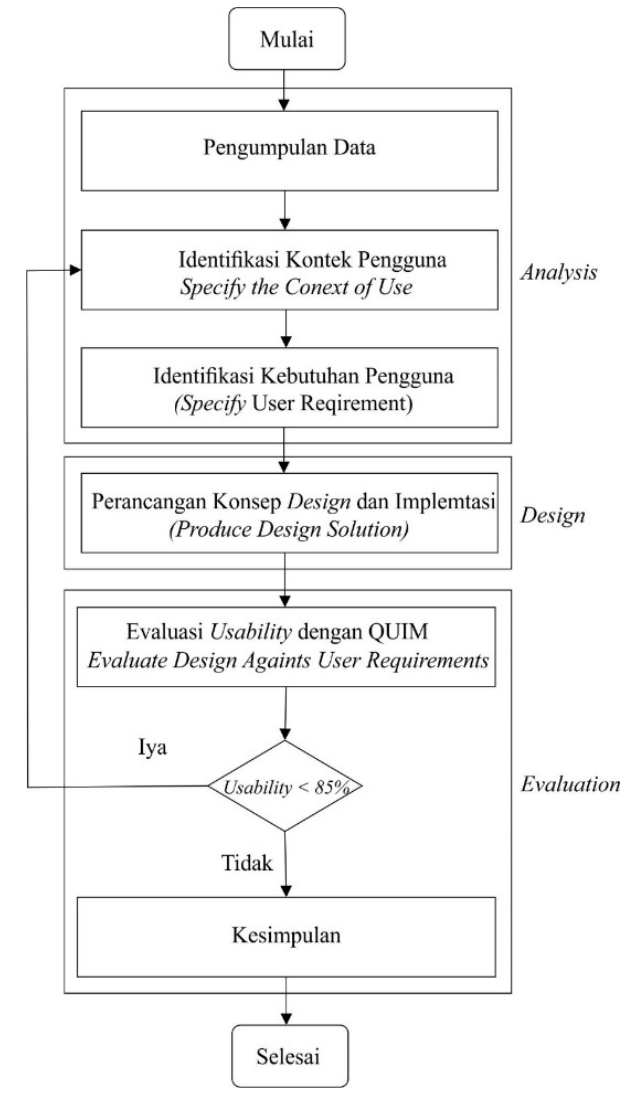

Gambar 1 Alur Pemodelan aplikasi game Belajar Bermain Angklung[6]

Berdasarkan Gambar 1, berikut ini penjelasan dari masing- masing tahapan yang dilakukan:

A. Pengumpulan Data

Pada tahap ini dilakukan evaluasi usablity dengan menggunakan QUIM [9] terhadap 3 aplikasi game angklung dalam berntuk kuesioner. Kuesioner tersebut telah diuji validitasnya menggunakan kolerasi 
Wahyu K. Hartanto et.al.

Pearson dan uji reabilitas menggunakan rumus alpha cronbach menyatakan kusioner bersifat reliabel. Selanjutnya dilakukan pengujian usability dan diperoleh hasil untuk semua faktor usability pada game angklung yang telah dievaluasi belum memenuhi batas minimum usability yang diterima. Diantaranya fitur yang tersedia pada aplikasi game angklung tersebut belum sesuai dengan kebutuhan dan kemampuan pengguna, serta penggunaan elemen visual dalam navigasi yang terdapat pada aplikasi game angklung belum dikenali fungsinya secara baik oleh pengguna. Selanjutnya dilakukan observasi kapada 5 orang user [6] untuk mengetahui kemampuan dan pemahaman pengguna dalam menggunakan smartphone dan aplikasi game angklung, hasilnya semua anak mampu mengoperasikan smartphone namun sebagian anak memiliki kendala dalam menggunakan game angklung. Setelah dilakukan observasi dilanjutkan dengan wawancara kepada pengguna yang bertujuan untuk mendapatkan data mengenai wawasan dan pengalaman pengguna menggunakan teknologi, angklung serta kebutuhan pengguna pada aplikasi. Adapun hasil dari wawancara tersebut berkaitan yang dengan teknologi, angklung dan kebutuhan aplikasi yang menggambarkan characteristic, behavior, needs dan motivation dari pengguna. Pada proses ini nantinya akan menghasilkan output untuk permodelan persona pada tahap specify the contect of use.

B. Specify the contect of use

Pada tahap ini dilakukan identifikasi konteks pengguna dengan membuat persona. Adapun persona yang dihasilkan yaitu pengguna merupakan yang murid Saung Angklung Udjo yang memiliki umur 15-17 tahun dan berjenis kelamin laki- laki. Device yang biasa pengguna pakai adalah smartphone dengan operating system Android. Pengguna juga dapat mengoperasikan smartphone dan pengguna biasa menggunakan smartphone selama 1 jam dan biasa menggunakan smartphone pada saat di rumah dan digunakan untuk bermain game online serta mengakses media sosial. Pengguna juga biasa bermain angklung pada saat di sanggar bersama teman- teman dan menjadikan angklung sebagai hobi serta melestarikan kebudayaan. Kebutuhan yang dibutuhkan pengguna berupa mendapatkan media belajar simulasi memainkan angklung, mendapatkan media berlatih angklung dengan menggunakan note/ nada, mendapatkan game yang terdapat petunjuk cara bermain, mendapatkan game yang memiliki warnawarni dan dilengkapi musik, mendapatkan game yang dapat dimainkan bersama teman-teman (multiplayer). Pada proses ini nantinya akan menghasilkan output berupa persona yang digunakan untuk menentukan kebutuhan pengguna pada tahap specify user and organizational requirements.

C. Specify user and organizational requirements

Pada tahap ini dilakukan identifikasi kebutuhan pengguna yang diperoleh dari tahap sebelumnya, hasil dari identifikasi pengguna berupa kebutuhan (needs) dari pengguna untuk menentukan kebutuhan (requirements) yang diperlukan oleh aplikasi. Adapun kebutuhan (needs) dari pengguna yaitu seperti mendapatkan media belajar simulasi memainkan angklung, mendapatkan media berlatih angklung dengan menggunakan nada, terdapat petunjuk cara bermain, memiliki warna atau tampilan sederhana dan dilengkapi musik, mendapatkan game yang dapat dimainkan bersama teman-teman (multiplayer). Setelah mengidentifikasi kebutuhan (needs) dari pengguna selanjutnya menentukan kebutuhan (requirements) yang diperlukan aplikasi yaitu fitur belajar bermain angklung (simulasi), mini game bermain angklung dengan menggunakan nada, petunjuk singkat cara bermain game, game yang memiliki tampilan dengan warna- warni dilengkapi dengan musik, game yang dapat dimainkan secara bersamasama (multiplayer).

D. Produce Design Solution

Pada tahap ini dilakukan perancangan konsep desain dengan merancang model konseptual dan membuat wireframe. Berdasarkan model konseptual dan wireframe dihasilkan mockup aplikasi belajar bermain angklung untuk selanjutnya diimplementasikan menjadi prototype.

E. Evaluate Design Againts User Requirements

Berdasarkan penerapan metode QUIM untuk mengevaluasi usability dengan menggunakan kuesioner yang sudah divalidasi sebelumnya terhadap 5 orang user. Menurut Jacob Nielsen [13], dengan jumlah 5 responden telah mendapatkan hasil pengujian mencapai lebih dari $85 \%$. Jika nilai usability lebih dari 85\% artinya model user interface sudah sesui dengan kebutuhan pengguna (meets requiirements), 
sebaliknya harus dilakukan proses perancangan ulang mulai dari tahap specify the context of use. Detail pembahasan terkait evaluasi usability dijabarkan pada bagian selanjutnya.

\section{HASIL DAN PEMBAHASAN}

Gambar 2 merupakan hasil prototype aplikasi game Belajar Bermain Angklung.

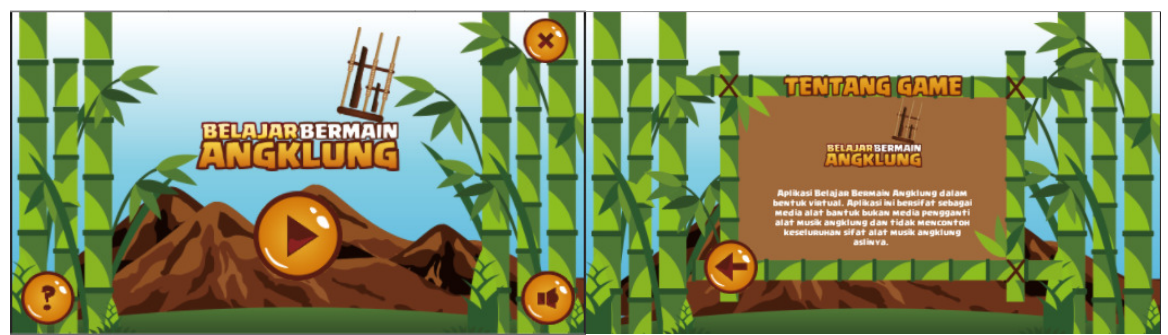

(a)

(b)

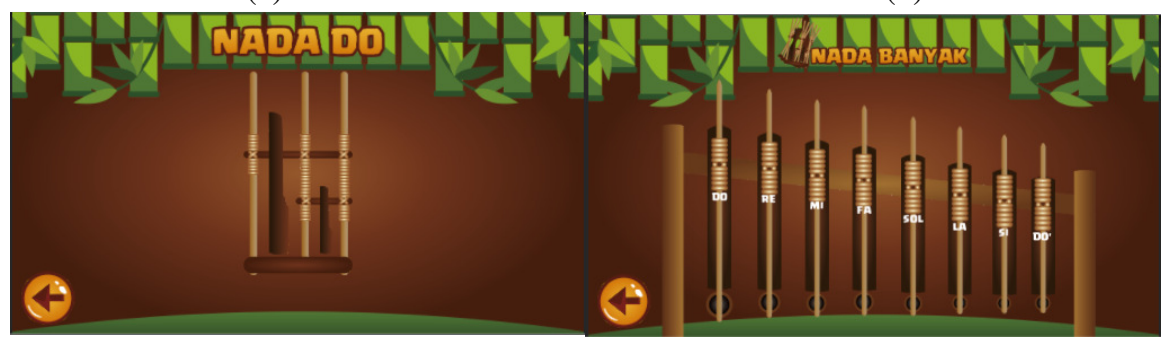

(c)

(d)

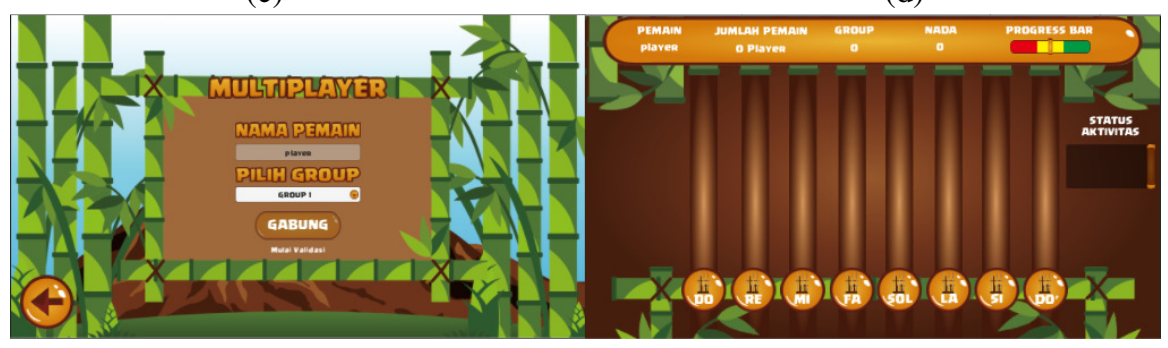

(e)

(f)

Gambar 2 prototype aplikasi belajar bermain angklung (a) halaman awal (b) informasi game (c) membunyikan angklung (d) membunyikan angklung (d) multiplayer (e) bermain angklung

Setelah melakukan evaluasi usability menggunakan kuesioner yang menerapkan faktor-faktor usabiliy dari QUIM terhadap protoytpe game Belajar Bermain Angklung, mengetahui persentase dari setiap faktor QUIM secara keseluruhan. Selanjutnya dilakukan perbandingan dengan hasil pengujian terhadap 3 aplikasi yang sebelumnya telah dijadikan sebagai sample. Gambar 3 berikut merupakan hasil evaluasi usability yang menerapkan faktor-faktor usabiliy dari QUIM terhadap prototype game Belajar Bermain Angklung dengan 3 aplikasi game angklung yang sudah dievaluasi sebelumnya 
Wahyu K. Hartanto et.al.

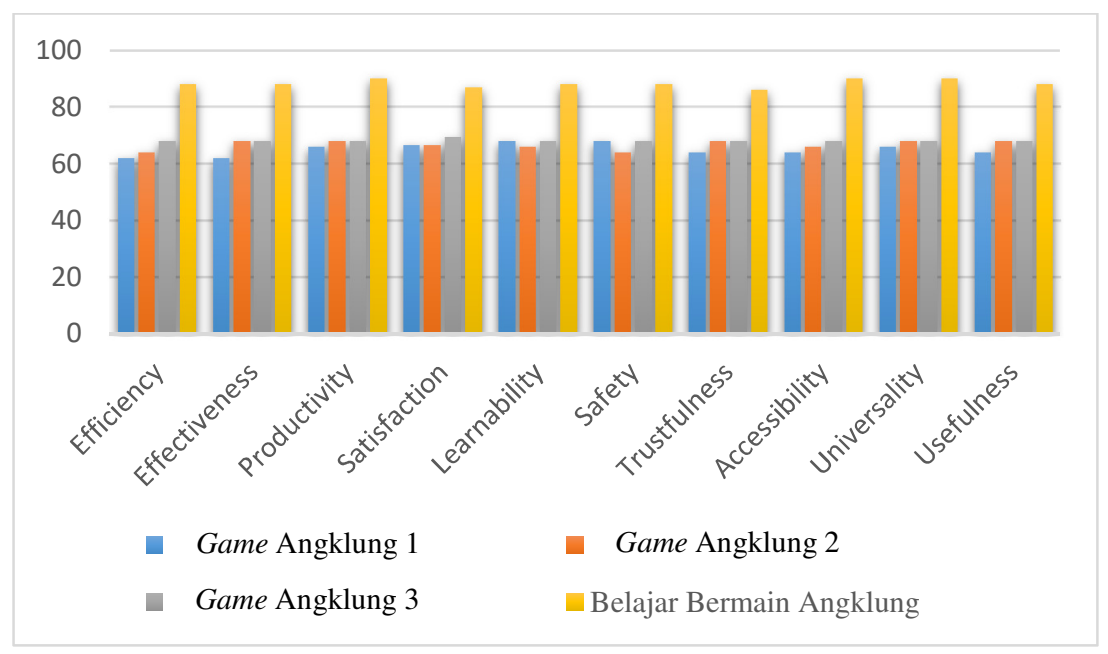

Gambar 3 Perbandingan hasil evaluasi usability

Berdasarkan Gambar 3 dapat dilihat persentase setiap faktor usability QUIM lebih dari 86\% sehingga aplikasi masuk ke dalam adjectif rating atau kategori yaitu excellent (sangat baik) sehingga tidak memerlukan perbaikan [5]. Pada Gambar 3 tersebut terlihat jelas bahwa prototype yang dirancang memiliki tingkat usability yang lebih baik karena fitur yang diberikan pada Aplikasi Game Belajar Bermain Angklung memenuhi kebutuhan serta kemampuan pengguna. Hal ini terlihat pada faktor productivity, learnability serta usefulness terjadi kenaikan persentase dengan nilai yang diperoleh sebesar 90\%, kenaikan pada faktor productivity, learnability serta usefulness karena penambahan fitur game yang dapat dimainkan bersama- sama (multiplayer) serta perubahan pada penyajian fitur belajar bermain angklung (simulasi), mini game bermain angklung dengan menggunakan nada, petunjuk singkat cara bermain game, game yang memiliki tampilan dengan warna-warni dilengkapi dengan musik yang menyesuaikan dengan kebutuhan serta kemampuan pengguna dalam menggunakan aplikasi game Belajar Bermain Angklung. Selain telah menyesuaikan kebutuhan dan kemampuan pengguna, penggunaan elemen visual serta navigasi yang digunakan pada aplikasi game Belajar Bermain Angklung dapat dikenali dengan baik fungsinya oleh pengguna. Hal ini terlihat pada faktor accessibility serta universality yang mengalami kenaikan persentase, kenaikan pada faktor accessibility karena menu yang ada pada aplikasi memberikan informasi yang jelas sehingga pengguna dengan mudah berpindah pada aplikasi game Belajar Bermain Angklung. selanjutnya kenaikan pada faktor universality karena penggunaan ikon dan button yang ditampilkan pada aplikasi game Belajar Bermain Angklung yang membuat pengguna dapat menjalankan fitur yang terdapat pada aplikasi game Belajar Bermain Angklung

\section{Kesimpulan}

Dari hasil analisis dan penggunaan metode user centered design pada perancangan user interface game Belajar Bermain Angklung untuk bermain angklung, ditarik kesimpulan bahwa didapatkan model user interface game angklung untuk belajar bermain angklung. Penambahan fitur game yang dapat dimainkan bersama- sama (multiplayer) dan perubahan pada penyajian fitur belajar bermain angklung (simulasi), mini game bermain angklung dengan menggunakan nada, petunjuk singkat cara bermain game, game yang memiliki tampilan dengan warna-warni dilengkapi dengan musik yang menyesuaikan dengan kebutuhan serta kemampuan pengguna dan elemen visual serta navigasi yang digunakan pada aplikasi game Belajar Bermain Angklung dapat dikenali dengan baik fungsinya oleh pengguna. Hal ini ditunjukan dengan hasil evaluasi usability dengan menggunakan kuesioner berdasarkan faktor-faktor usability dari QUIM, diperoleh nilai usability terendah sebesar $86 \%$ sehingga masuk dalam kategori sangat baik dan memenuhi aspek usability, atau dengan kata lain prototype yang dihasilkan sesuai dengan kebutuhan pengguna dalam belajar bermain angklung. 
Pengembangan lebih lanjut terhadap prototype game Belajar Bermain Angklung, pada fitur bermain angklung adalah penambahan fitur untuk menambahkan lagu yang dimainkan. Selain itu teknik bermain angklung perlu disesuaikan dengan kondisi riil yaitu digoyang serta pengaturan suara yang dihasilkan menyesuaikan dengan panjang maupun pendeknya suatu nada.

\section{DAFTAR PUSTAKA}

[1] M. G. B. Madegani dan V. Atika, "KARAKTERISTIK ANGKLUNG BERBAHAN BAMBU APUS (Gigantochloa apus) Characteristics of Bamboo “Apus" (Gigantochloa apus) Angklung," D i n a m i k a Ke raj i n a n d a n B a t $i k$, vol. 32, no. 1, pp. 41-50, Juni 2015.

[2] DPRD KOTA BANDUNG, "PERDA 05-2012 TENTANG PELESTARIAN SENI TRADISIONAL," 2015.

[3] W. O. Galitz, The Essential Guide to User Interface Design Second Edition, Canada: Wiley Publishing, Inc, 2007.

[4] N. S. Aziz, A. Kamaludin dan N. Sulaiman, “ASSESSING WEB SITE USABILITY MEASUREMENT,” International Journal of Research in Engineering and Technology, vol. 02, no. 09, 2013.

[5] A. Bangor, P. Kortum and J. Miller, "Determining What Individual SUS Score Mean: Adding an Adjective Rating Scale," Jurnal Of Usability Studies, vol. IV, no. 3, pp. 114-123, 2009.

[6] T. Lowdermik, A Developer's Guide to Building User-Friendly Applications User-Centered Design, United States of America : O'Reilly Media, Inc, 2013.

[7] J. J. Garrett, The Elements of User Experience: User-Centered Design for the Web and Beyond,, United States of America, 2011.

[8] A. Seffah, M. Donyaee, R. B. Kline dan H. K. Padda, Usability measurement and metrics: a Consolidated model, Software Qual J, 2016.

[9] A. H. M KATY, MEASURING USABILITY FOR APPLICATION SOFTWARE USING THE QUALITY IN USE INTEGRATION MEASUREMENT MODEL, Malaysia: aculty of Computer Science and Information Technology Universiti Tun Hussein Onn Malaysia, 2016.

[10] J. Rubin dan D. Chisnell, Handbook of Usability Testing Second Edition, Canada: Wiley Publishing Inc, 2008.

[11] D. A. PRASETYOWATI, M.Stat, ANALISIS STATISTIK (TEORI DAN APLIKASI MENGGUNAKAN SPSS), Lampung: FAKULTAS ILMU KOMPUTER UNIVERSITAS GLOBAL MANDIRI, 2016.

[12] A. Setiawan, ANALISIS DATA STATISTIK, Salatiga: Tisara Grafika Salatiga, 2017.

[13] J. Nielsen, "Why You Only Need to Test with 5 Users," [Online]. Available: https://www.nngroup.com/articles/why-you-onlyneed-to-test-with-5-users/. [Accessed 15 Maret 2018]. 
